\title{
El concepto de dignidad humana y la utopía realista de los derechos humanos*
}

\author{
JÜRGEN HABERMAS \\ Profesor Emérito \\ Universidad de Fráncfort
}

\begin{abstract}
Resumen: En este artículo Habermas defiende la tesis que sostiene que siempre ha existido una conexión interna entre la noción moral de dignidad humana y la concepción jurídica de los derechos humanos, aunque ésta sólo se haya manifestado de manera explícita en el pasado reciente. Contra posturas escépticas y estrategias deflacionarias, sostiene que el concepto de dignidad humana no es una expresión clasificatoria vacía, sino que, por el contrario, es la fuente de la que derivan todos los derechos básicos (en la experiencia concreta de violaciones a la dignidad humana), además de ser la clave para sustentar la indivisibilidad de todas las categorías (o generaciones) de los derechos humanos. A través de una reconstrucción histórica y conceptual de dos tradiciones diferentes, demuestra cómo la idea de la dignidad humana sirve como un "portal" a través del cual la sustancia igualitaria y universalista de la moral se traslada al derecho.
\end{abstract}

Palabras clave: dignidad humana, derechos individuales, respeto igualitario

\begin{abstract}
In this article, Habermas wants to defend the thesis that a conceptual connection between the moral notion of human dignity and the juridical conception of human rights has always existed, even if it has only become explicit in the recent past. Against skeptical positions or deflationary strategies, he wants to maintain that the concept of human dignity is not merely an empty classificatory expression, but rather, the source from which all the basic rights derive their sustenance (in concrete experiences of violations of human dignity), as well as the key to ground the indivisibility of all the categories (or generations) of human rights. Through a historical and conceptual reconstruction of the interconnections of two different traditions, he demonstrates how the idea of human dignity becomes the "portal" through which the egalitarian and universalistic substance of morality is imported into the law.
\end{abstract}

Key words: human dignity, individual rights, equal respect

El artículo $1^{\circ}$ de la Declaración Universal de los Derechos Humanos, adoptada por las Naciones Unidas el 10 de diciembre de 1948, inicia con la siguiente afirmación: "Todos los seres humanos nacen libres e

*El Comité de Dirección desea agradecer al profesor Habermas su interés en publicar este artículo en Diánoia, y a los doctores María Herrera y Eduardo Mendieta, su valiosa colaboración en el proceso editorial. 
iguales en dignidad y derechos." ${ }^{1}$ Con el mismo espíritu, el preámbulo de la Declaración se refiere a la dignidad humana y los derechos humanos al reafirmar la "fe en los derechos fundamentales del hombre, en la dignidad y el valor de la persona humana". La Ley Fundamental de la República Federal Alemana, promulgada hace sesenta años, inicia también con una sección dedicada a los derechos fundamentales (Grundrechte); el artículo $1^{\circ}$ de esta sección abre con la afirmación siguiente: "La dignidad humana es inviolable." Anteriormente habían aparecido afirmaciones similares en tres de las cinco constituciones políticas alemanas promulgadas entre 1946 y 1949. En la actualidad, la "dignidad humana" ostenta un lugar prominente en el discurso de los derechos humanos y la toma de decisiones judiciales. ${ }^{2}$

La inviolabilidad de la dignidad humana reclamó la atención del público alemán cuando la Corte Constitucional Federal declaró inconstitucional la Ley de Seguridad Aérea en el año 2006. Al momento de promulgarla, el parlamento tenía en mente el escenario internacional creado el 11 de septiembre [de 2001] por el ataque terrorista a las torres gemelas en el World Trade Center [de la ciudad de Nueva York]. En dicha ley se pretendía autorizar a las fuerzas armadas para que, en una situación similar, pudieran derribar un avión de pasajeros que se hubiera convertido en un proyectil viviente, previniendo así la amenaza a un número incierto aunque considerable de personas que se encontraran en tierra. Para la corte, sin embargo, la muerte de los pasajeros producida en esas circunstancias por agentes estatales constituía una acción no amparada por el orden constitucional alemán. La corte argumentó que el deber del Estado (conforme al artículo 2.2. GG) ${ }^{3}$ de proteger la vida de las víctimas potenciales de un ataque terrorista era secundario frente al deber de respetar la dignidad humana de los pasajeros. "La manera en la que el Estado podría haber dispuesto unilateralmente de la vida de las personas a bordo del avión les habría negado el valor debido por sí mismo a todo ser humano." ${ }^{4}$ Sin lugar a dudas, el eco del imperativo categórico kantiano se escucha en las palabras de la corte. El respeto a la dignidad de todo ser humano prohíbe que el Estado

${ }^{1}$ La primera frase del preámbulo aboga, a la vez, por el reconocimiento de la "dignidad intrínseca" y de los "derechos iguales e inalienables de todos los miembros de la familia humana".

${ }^{2}$ Denninger 2009a.

3 "Toda persona tiene derecho a la vida y a la integridad física."

${ }^{4}$ BverfG, 1 BvR 357/05 vom 15.02.2006, Absatz-Nr. 124. (Véase la versión en inglés en <http://www.bundesverfassungsgericht.de/entscheidungen/rs20060215 _1bvr035705en.html>.) Sobre el juicio, véase Bernstorff, inédito, 2008.

Diánoia, vol. LV, no. 64 (mayo 2010). 
trate a una persona simplemente como un medio para alcanzar un fin, incluso si ese otro fin fuera el de salvar la vida de muchas otras personas. ${ }^{5}$

Vale la pena resaltar el hecho de que la dignidad humana, como concepto filosófico que ya existía en la Antigüedad y que adquirió su expresión canónica actual con Kant, sólo alcanzó a materializarse en textos de derecho internacional y en las constituciones nacionales recientes hasta después de la Segunda Guerra Mundial. Únicamente durante las últimas décadas la dignidad humana ha desempeñado un papel protagónico en la jurisdicción internacional. De manera contrastante, la noción de dignidad humana no apareció como concepto legal ni en las declaraciones clásicas de los derechos humanos del siglo XVIII, ni en las codificaciones del siglo XIX. ${ }^{6}$ ¿Por qué el discurso de los derechos humanos obtuvo una importancia legal prominente con tanta anterioridad al discurso de la dignidad humana? Ciertamente, los documentos fundacionales de las Naciones Unidas que establecieron una conexión explícita entre los derechos humanos y la dignidad humana fueron una respuesta clara a los crímenes masivos cometidos bajo el régimen nazi y las masacres de la Segunda Guerra Mundial. Pero, ¿puede esto dar cuenta también del lugar destacado que se le otorgó a la dignidad humana en las constituciones de la posguerra de Alemania, Italia, y Japón, y de igual forma en los regímenes sucesivos de los países que causaron y participaron directamente en esa catástrofe moral del siglo XX? ¿O únicamente en el marco histórico del Holocausto la idea de los derechos humanos se convirtió, de manera casi retrospectiva, en una idea moralmente cargada - y tal vez sobrecargada - con el concepto de dignidad humana?

La manera en que se acude al concepto de "dignidad humana" en las discusiones constitucionales y sobre legislación internacional recientes parece apoyar esta idea. Existe solamente una excepción a mediados del siglo XIX: en la justificación de la abolición de la pena de muerte y del castigo corporal del $\S 139$ de la Constitución alemana de marzo de 1849, donde se encuentra la siguiente afirmación: "Un pueblo libre

${ }^{5}$ Kant define el concepto de dignidad como un requerimiento moral que exige tratar a toda persona como un fin en sí mismo. Las palabras de Kant son las siguientes: "[Todo] tiene o un precio o una dignidad. Lo que tiene un precio puede ser sustituido por otra cosa como equivalente; en cambio, lo que se halla por encima de todo precio y, por tanto, no admite equivalente, posee dignidad" (Kant 2003, p. 74 (4: 434)). [Las referencias entre paréntesis corresponden a la numeración de las obras completas en alemán. ( $N$. del t.)]

${ }^{6}$ McCrudden 2008.

Diánoia, vol. LV, no. 64 (mayo 2010). 
debe respetar la dignidad humana incluso en el caso de un criminal." ${ }^{7}$ Pero esta constitución, producto de la primera revolución burguesa de Alemania, nunca entró en vigor. De cualquier modo, resulta bastante llamativa la discontinuidad temporal que existe entre la historia de los derechos humanos - iniciada en el siglo XVII- y la relativamente reciente aparición —a mediados del siglo pasado- del concepto de dignidad humana en codificaciones nacionales, en el derecho internacional y la administración de la justicia.

Sin embargo, contra la suposición que atribuye solamente una carga moral retrospectiva a los derechos humanos, me gustaría defender la tesis de que siempre ha existido - aunque inicialmente sólo de modo implícito- un vínculo conceptual interno entre los derechos humanos y la dignidad humana. Nuestra intuición nos dice, en cualquier caso, que los derechos humanos han sido producto de la resistencia al despotismo, la opresión y la humillación. Hoy en día ninguna persona podría pronunciar esos venerables artículos - por ejemplo, el artículo $5^{\circ}$ de la Declaración Universal: "Nadie será sometido a torturas ni a penas o tratos crueles, inhumanos o degradantes" - sin escuchar en ellos el clamor de las innumerables criaturas humanas torturadas y asesinadas. La defensa de los derechos humanos se nutre de la indignación de los humillados por la violación de su dignidad humana. De modo que si esto configura su punto de partida histórico, tendrían que estar también presentes vestigios del vínculo conceptual entre la dignidad humana y los derechos humanos desde los inicios del desarrollo del derecho mismo (Recht). De esta manera, nos enfrentamos a la pregunta de si la "dignidad humana" es un concepto normativo fundamental y sustantivo, a partir del cual los derechos humanos pueden ser deducidos mediante la especificación de las condiciones en que son vulnerados, o si, por el contrario, se trata de una expresión que simplemente provee una fórmula vacía que resume un catálogo de derechos humanos individuales no relacionados entre sí.

Quiero ofrecer algunas razones legales para mostrar que la "dignidad humana" no es únicamente una expresión clasificatoria, como si se tratara de un parámetro de sustitución vacío que agrupara una multiplicidad de fenómenos diferentes. Por el contrario, pretendo sostener (I) que constituye la "fuente" 8 moral de la que todos los derechos fundamentales derivan su sustento. (II) A continuación presentaré, por un lado, un análisis de la función catalizadora desempeñada por el concep-

${ }^{7}$ Denninger 2009a, p. 1.

${ }^{8}$ Como se afirma en la Constitución del Estado de Sajonia, promulgada en 1989.

Diánoia, vol. LV, no. 64 (mayo 2010). 
to de dignidad en la construcción de los derechos humanos, en términos de una historia conceptual y a partir de la moral racional; y, por otro, en la forma de derechos subjetivos. Por último, (III) mostraré cómo el origen de los derechos humanos en la noción moral de dignidad humana puede dar cuenta de la fuerza política explosiva de la utopía concreta que me gustaría defender, tanto contra el rechazo generalizado de los derechos humanos (Carl Schmitt), como de los intentos más recientes por quitarle filo a su fuerza radical.

Debido a su carácter abstracto, los derechos fundamentales necesitan ser especificados en términos concretos en cada caso particular. En este proceso, en contextos culturales diferentes los legisladores y jueces suelen llegar a resultados diferentes; hoy en día esto puede verse, por ejemplo, en la regulación de asuntos éticos controvertidos como el suicidio asistido, el aborto y la manipulación genética. Es indudable también que, en virtud de esa necesidad de interpretación, los conceptos legales universales facilitan la negociación de acuerdos. Así, apelar al concepto de dignidad humana sin duda posibilitó que se llegara a un consenso traslapado, por ejemplo, en la fundación de las Naciones Unidas. Por la misma razón se invoca este concepto para negociar tratados de derechos humanos en convenciones legales internacionales y para dirimir disputas legales internacionales entre partes de culturas diferentes: "Todo el mundo podía estar de acuerdo en que la dignidad humana era algo central, pero no por qué ni cómo."9

A pesar de esta observación, el significado jurídico de la dignidad humana no se agota en la función de crear una cortina de humo para ocultar diferencias más profundas. El hecho de que el concepto de "dignidad humana" también pueda ocasionalmente facilitar acuerdos al momento de precisar y extender los derechos humanos mediante la neutralización de diferencias abismales no puede servir como explicación para su tardía aparición como concepto legal. En este contexto, me gustaría argumentar que las condiciones históricas cambiantes simplemente nos han hecho conscientes de algo que ya estaba inscrito desde el inicio en los derechos humanos: el sustrato normativo de la igual dignidad de cada ser humano que los derechos humanos únicamente precisan con más detalle. De ese modo, los jueces apelan a la protección de la dig-

${ }^{9}$ McCrudden 2008, p. 678. También sobre este tema, el autor habla de "domesticar y contextualizar los derechos humanos" (2008, pp. 719 ss.).

Diánoia, vol. LV, no. 64 (mayo 2010). 
nidad humana cuando, por ejemplo, los riesgos no previstos de nuevas tecnologías invasivas los llevan a introducir un nuevo derecho, como en el caso del derecho a la autodeterminación informativa (Informationelle Selbstbestimmung). ${ }^{10}$

De ahí que la experiencia de violaciones a la dignidad humana haya desempeñado en muchos casos, y pueda desempeñar aún, una función creativa: ya sea ante las insoportables condiciones de vida y la marginación de las clases sociales empobrecidas; o ante el trato desigual a hombres y mujeres en el lugar de trabajo, o la discriminación de extranjeros y minorías raciales, religiosas, lingüísticas o culturales; o también ante la terrible experiencia de mujeres jóvenes provenientes de familias inmigrantes que tienen que liberarse ellas mismas de la violencia de códigos de honor tradicionales; o, por último, ante la brutal expulsión de inmigrantes ilegales y solicitantes de asilo. A la luz de tales retos históricos específicos, diferentes aspectos del significado de la dignidad humana surgen desde la plétora de experiencias de lo que significa ser humillado y herido profundamente. Los aspectos de la dignidad humana especificados y actualizados de esta manera podrían conducir tanto al agotamiento más acentuado de los derechos civiles existentes, como al descubrimiento y construcción de nuevos derechos. A través de este proceso, la intuición subyacente de la humillación labra su camino antes que nada en la conciencia de los individuos maltratados y, después, en los textos legales donde encuentra su articulación y elaboración conceptual.

La Constitución de la República de Weimar de 1919, pionera en la implementación de los derechos sociales fundamentales, sirve para ejemplificar lo anterior: el artículo 151 habla de "alcanzar una vida digna para todas las personas". Allí, el concepto de dignidad humana se esconde tras el uso de una expresión coloquial, pero ya en 1944 la Organización Internacional del Trabajo (OIT) emplea la retórica de la dignidad humana en el mismo contexto sin calificativo alguno. Es más, apenas unos años después, el artículo 22 de la Declaración Universal de los Derechos Humanos aboga también por garantías para los derechos económicos, sociales y culturales, de tal forma que todo individuo pueda vivir en las condiciones que son "indispensables para su dignidad y el libre desarrollo de su personalidad". Desde entonces solemos hablar de las "generaciones" sucesivas de los derechos humanos. La función heurística de la dignidad humana es la clave para entender

${ }^{10}$ Sobre este tema, McCrudden habla de "justificar la creación de nuevos derechos y justificar la extensión de los ya existentes" (2008, p. 721).

Diánoia, vol. LV, no. 64 (mayo 2010). 
las interconexiones lógicas que existen entre estas cuatro categorías de derechos.

Los derechos liberales, que cristalizan en torno a la inviolabilidad y seguridad de la persona, del libre comercio y el libre ejercicio de la religión, fueron establecidos para prevenir la intromisión estatal en la esfera privada y constituyen, junto con los derechos democráticos de participación, el conjunto de los así llamados derechos civiles clásicos. Sin embargo, en la práctica, los ciudadanos tienen iguales oportunidades para hacer uso de estos derechos sólo si de forma simultánea disfrutan también de garantías para tener un nivel suficiente de independencia en su vida privada y en su situación económica y si, además, tienen la posibilidad de formar identidades personales en un entorno cultural escogido por ellos mismos. Las experiencias de exclusión, maltrato y discriminación nos enseñan que los derechos civiles clásicos adquieren "igual valor" (Rawls) para todos los ciudadanos únicamente cuando se complementan con derechos sociales y culturales. Los reclamos para tener acceso a un reparto adecuado de la prosperidad y la cultura en la sociedad plantean límites estrechos a la pretensión de transferir los costos y riesgos sistémicos a los individuos. Dichas exigencias tienen por objeto evitar la profundización de las desigualdades sociales y la exclusión de algunos grupos de la vida social y cultural, de ahí que algunas de las políticas que han predominado en décadas recientes, no sólo en Estados Unidos y Gran Bretaña, sino también en la Europa continental y, de hecho, alrededor del mundo - por ejemplo, aquellas que pretenden asegurar una vida autónoma a los ciudadanos primordialmente a través de la garantía de libertades económicas- tienden a destruir el equilibrio entre las diferentes categorías de los derechos fundamentales. La dignidad humana, que es una y la misma en todas partes y para todo ser humano, fundamenta la indivisibilidad de todas las categorías de los derechos humanos. Únicamente sobre la base de una colaboración recíproca, los derechos fundamentales pueden cumplir la promesa moral de respetar por igual la dignidad humana de cada persona. ${ }^{11}$

El protagonismo creciente de la dignidad humana explica también el papel manifiesto que recientemente ha tenido este concepto en la administración de la justicia. En la medida en que los derechos civiles se difunden con mayor profundidad en todo el sistema legal, su influencia se extiende y adquiere mayor alcance, más allá de la relación vertical entre los ciudadanos individuales y el estado, hasta llegar a

${ }^{11}$ Lohmann 2005.

Diánoia, vol. LV, no. 64 (mayo 2010). 
impregnar las relaciones horizontales entre los individuos y los grupos sociales. Como resultado, se presentan con mayor frecuencia conflictos que requieren equilibrar exigencias contrapuestas que se esgrimen a nombre de los derechos fundamentales. ${ }^{12}$ Una decisión justificada en casos difíciles (hard cases) suele ser posible únicamente si se apela a una violación de la dignidad humana, cuya validez absoluta fundamenta la prioridad de una de las exigencias sobre la otra. En el discurso judicial, por lo tanto, el papel de este concepto dista mucho de ser un vago parámetro de sustitución que opera ante la ausencia de una conceptualización de los derechos humanos. La "dignidad humana" desempeña la función de un sismógrafo que registra lo que es constitutivo de un orden democrático legal, a saber: precisamente aquellos derechos que los ciudadanos de una comunidad política deben concederse a sí mismos si son capaces de respetarse entre sí, como miembros de una asociación voluntaria entre personas libres e iguales. La garantía de estos derechos humanos da origen al estatus de ciudadano de quienes, como sujetos de iguales derechos, tienen la facultad de exigir ser respetados en su dignidad humana.

Después de doscientos años de historia constitucional moderna, poseemos ya un mejor entendimiento de lo que distinguió este desarrollo desde sus inicios: la dignidad humana configura el portal a través del cual el sustrato igualitario y universalista de la moral se traslada al ámbito del derecho. La idea de la dignidad humana es el eje conceptual que conecta la moral del respeto igualitario de toda persona con el derecho positivo y el proceso de legislación democrático, de tal forma que su interacción puede dar origen a un orden político fundado en los derechos humanos. Ciertamente, cuando las declaraciones clásicas de los derechos humanos se refieren a los derechos "innatos" o "inalienables", a los derechos "inherentes" o "naturales", o a los droits inaliénables et sacrés, delatan sus orígenes religiosos y metafísicos: "Sostenemos como evidentes por sí mismas dichas verdades [...], que todos los hombres son creados con ciertos derechos inalienables". Ahora bien, para un estado secular, tales afirmaciones funcionan primordialmente como parámetros de sustitución: nos alertan sobre un modo especial de justificación generalmente aceptable cuya dimensión epistémica se encuentra más allá del control del estado. Los "padres fundadores" reconocieron, además, que los derechos humanos, a pesar de su simple y llana justificación

${ }^{12}$ La discusión en torno al llamado efecto horizontal [Drittwirkung] de los derechos fundamentales, que se llevó a cabo en Europa en la última mitad del siglo pasado, ha encontrado eco recientemente en Estados Unidos. Véase Gardbaum 2003, pp. 399-459.

Diánoia, vol. LV, no. 64 (mayo 2010). 
moral, requieren una "declaración" democrática y deben ser aplicados de manera constructiva en el interior de una comunidad política establecida.

En virtud de que la promesa moral de igual respeto a todo ser humano debe ser cambiada a una moneda legal, los derechos humanos exhiben un rostro que, como el de Jano, observa simultáneamente la moral y el derecho. ${ }^{13}$ A pesar de su contenido exclusivamente moral, los derechos humanos tienen la forma de derechos subjetivos exigibles que conceden libertades y pretensiones específicas. Han sido diseñados para ser traducidos en términos concretos en la legislación democrática; para ser especificados, caso por caso, en las decisiones judiciales, y para hacerlos valer en casos de violación. De modo que los derechos humanos se circunscriben de manera precisa sólo en aquella parte de la moral que puede ser traducida al ámbito de la ley coercitiva y transformarse en una realidad política mediante la fórmula robusta de derechos civiles efectivos. ${ }^{14}$

En esta categoría enteramente nueva de derechos se reunifican dos elementos que se habían separado antes, en el curso de la desintegración del derecho natural cristiano, y que se desarrollaron posteriormente en direcciones opuestas. El resultado de esta diferenciación fue, por una parte, la moral internalizada y justificada racionalmente, anclada en la conciencia individual —que Kant confina por entero al dominio de lo

${ }^{13}$ Lohmann 1998.

${ }^{14}$ Esto no constituye una revisión, sino solamente un complemento a mis reflexiones previas sobre los derechos humanos. Véanse Habermas 1998, pp. 184-197, y 2001. Los derechos humanos difieren de los derechos morales en que los primeros están orientados hacia la institucionalización y requieren un acto colectivo de formación de la voluntad, mientras que los sujetos morales se relacionan entre sí como personas sin necesidad de mediaciones al estar inscritos en una red de derechos y deberes morales (cfr. Flynn 2003, pp. 437-444). Sin embargo, al principio no tuve en cuenta los dos aspectos siguientes: primero, las experiencias acumuladas de humillaciones a la dignidad humana que constituyeron una fuente de motivaciones morales para incorporar, a finales del siglo XVIII y sin precedentes históricos, la práctica de la elaboración de constituciones. Segundo, la noción generadora del estatus del reconocimiento social a la dignidad de las personas que funciona como puente conceptual entre la idea moral del respeto igualitario para todos y la forma legal de los derechos humanos. Dejo por ahora de lado la pregunta de si este cambio de punto de vista tiene consecuencias adicionales para la lectura deflacionaria del principio discursivo "D" como parte de la justificación de los derechos fundamentales (cfr. Habermas 2006b). 
trascendental - y, por otra, el derecho promulgado positivo y coercitivo, que sirvió a los gobernantes absolutistas y a las asambleas tradicionales de los estados como instrumento para construir las instituciones del estado moderno y la sociedad de mercado. El concepto de derechos humanos es el producto de una síntesis inverosímil entre estos dos elementos: la "dignidad humana" sirvió así como el eje conceptual que permitió establecer dicha conexión. Esto me lleva a dirigir brevemente la mirada a la historia conceptual, en el curso de la cual los antiguos conceptos romanos y cristianos de la "dignidad humana" se transformaron en el proceso de esta síntesis moderna. Es de especial interés en este proceso un elemento conceptual adicional; a saber, la noción de dignidad social, en el sentido de la idea del honor asociado con los "estatus" particulares de las sociedades estratificadas de la Europa medieval y de la Europa moderna temprana. ${ }^{15}$ Debo reconocer que la hipótesis que voy a desarrollar requiere aún mayor investigación, tanto en lo referente a la historia conceptual que voy a presentar, como en lo que respecta a la propia historia de las revoluciones europeas.

Me gustaría, entonces, simplemente resaltar dos aspectos: por una parte, (a) la función mediadora de la "dignidad humana" en el cambio de perspectiva que tuvo lugar con el paso de los deberes morales a exigencias legales, y por otra, (b) la paradójica generalización de un concepto de dignidad que no estaba originalmente orientado a la distribución igualitaria de la dignidad, sino que, por el contrario, servía como indicador de diferencias de estatus.

(a) Las doctrinas modernas de la moral y del derecho, que afirman estar basadas por entero en la razón humana, comparten los conceptos de autonomía individual e igual respeto para todas las personas. Esta fundamentación común de la moral y del derecho suele oscurecer la diferencia decisiva entre la moral, que impone deberes con otras personas y que abarca, sin excepción, todas las esferas de la acción, y el derecho moderno, que crea dominios bien definidos de elecciones privadas en el curso de la vida de cada individuo. Bajo la premisa revolucionaria que sostiene que está permitido todo lo que no está explícitamente prohibido por la ley, los derechos subjetivos, y no los deberes, constituyen el punto de partida de la construcción de los sistemas legales modernos. Para Hobbes, así como para el derecho moderno en general, el principio guía es el de que todas las personas pueden actuar como

${ }^{15}$ Acerca de la evolución del concepto legal de la dignidad humana mediante la generalización de la dignidad vinculada al estatus, véase Waldron 2007.

Diánoia, vol. LV, no. 64 (mayo 2010). 
lo deseen, o se les permite abstenerse de actuar, dentro de los límites establecidos por la ley. Los actores asumen una perspectiva diferente cuando en vez de cumplir con deberes morales acuden a sus derechos. En una relación moral, las personas se preguntan por lo que deben a los otros, independientemente de su relación social con ellos, esto es: de cuánto los conocen, cómo se comportan y qué esperarían de ellos. En una relación legal, en cambio, lo que interesa a los individuos son las posibles exigencias o reclamaciones que podrían provenir de otras personas. En una comunidad legal, una persona adquiere obligaciones como resultado de las demandas que un tercero presenta ante ella. ${ }^{16}$ Por ejemplo, en el caso de un oficial de policía que quisiera obtener la confesión de un sospechoso mediante la amenaza ilegal de tortura; en cuanto persona moral, la simple amenaza como tal aun sin hacer referencia al acto efectivo de infligir dolor sería suficiente para desarrollar una mala conciencia sin importar el comportamiento del transgresor; por el contrario, la relación legal entre el agente de policía que estuviera actuando ilegalmente y el individuo sometido a interrogatorio sólo se actualizaría cuando este último se defendiera y emprendiera las acciones legales necesarias para hacer valer sus derechos (o cuando un defensor público actuara en su nombre). Naturalmente, en ambos casos, la persona amenazada es la fuente de las exigencias normativas que se violan con la tortura. No obstante, el hecho de que las acciones en cuestión transgredan normas morales es todo lo que se requiere para atribuirle al infractor una mala conciencia, mientras que en el caso de la relación legal, aquello que es objetivamente vulnerado se mantiene latente hasta que una demanda lo actualice.

Así, para Klaus Günther, la "transición de las obligaciones morales recíprocas a los derechos recíprocamente establecidos y acordados"17 puede interpretarse como el paso de un momento de "autoempoderamiento a uno de autodeterminación". La transición de la moral al derecho exige un cambio desde perspectivas simétricamente entrelazadas de respeto y estima por la autonomía del otro, a perspectivas que dan origen a la posibilidad de exigirle al otro el reconocimiento de la autonomía personal. La preocupación moralmente impuesta por la vulnerabilidad del otro es reemplazada por la demanda autojustificada

\footnotetext{
${ }^{16}$ Lohmann 1998, p. 66: "Un derecho moral cuenta como justificado cuando existe un deber moral correspondiente que, por sí mismo, cuenta ya como justificado; un derecho legal, en cambio, cuenta como justificado cuando forma parte de un sistema legal positivo que puede reclamar legitimidad como un todo."

${ }^{17}$ Algo que Lohmann parece malinterpretar como la transición de una moralidad tradicional a una ilustrada (veáse 1998, p. 87).
} 
(self-confident) del reconocimiento legal que se posee en virtud de ser un sujeto autodeterminado (self-determined) que "vive, siente y actúa de acuerdo con su propio juicio". ${ }^{18}$ De manera que el reconocimiento legal demandado por los ciudadanos va más allá del reconocimiento moral recíproco entre sujetos responsables, y posee el significado concreto del respeto exigido por un estatus que es merecido y que, como tal, se encuentra impregnado de las connotaciones de "dignidad" que en el pasado se asociaban al hecho de pertenecer a ciertos cuerpos corporativos socialmente respetados.

(b) El concepto concreto de dignidad o de "honor social" pertenece al mundo de las sociedades tradicionales organizadas jerárquicamente. En esas sociedades, una persona podía derivar la dignidad y respeto debidos, por ejemplo, del código de honor de la nobleza, o del ethos de los gremios de los oficios o profesiones, o aun del espíritu corporativo de las universidades. Cuando estas dignidades dependientes del estatus, que se daban siempre en plural, se fusionaron con la idea de la dignidad universal de todos los seres humanos, esta nueva dignidad abstracta se despojó de las características particulares de los ethos corporativos. Al mismo tiempo, sin embargo, la dignidad universalizada que se predica de todas las personas por igual preserva la connotación del respeto propio (self-respect) que depende del reconocimiento social. Como forma de dignidad social, la dignidad humana también requiere estar anclada a un estatus social; esto es, como pertenencia a una comunidad situada espacial y temporalmente, sólo que en este caso el estatus debe ser el mismo para todos. Así, el concepto de dignidad humana transfiere el contenido de una moral basada en el respeto igualitario al orden del estatus de ciudadanos que derivan el respeto propio del hecho de ser reconocidos por todos los demás ciudadanos como sujetos de derechos iguales y exigibles.

En este contexto, no es poco importante el hecho de que este estatus solamente pueda ser establecido dentro del marco de un estado constitucional, y que nunca pueda surgir por motu proprio. A su vez, este marco debe ser creado por los ciudadanos mismos, acudiendo a los medios que proporciona el derecho positivo, y debe ser protegido al desarrollarse en condiciones históricamente cambiantes. Como concepto legal moderno, la dignidad humana se encuentra asociada con el estatus que los ciudadanos asumen en ese orden político autogenerado (self-created). Como sus destinatarios, los ciudadanos pueden llegar a

${ }^{18}$ Günther, inédito, 2009b, pp. 13 ss.

Diánoia, vol. LV, no. 64 (mayo 2010). 
disfrutar de los derechos que protegen su dignidad humana si y sólo si primero se vinculan como los autores de la tarea democrática de establecer y mantener un orden político basado en los derechos humanos. ${ }^{19}$ Desde la perspectiva de esa comunidad de ciudadanos autolegisladores (self-legislating), la dignidad conferida por el estatus de la ciudadanía democrática se alimenta de la valoración republicana de una orientación hacia el bien común. Esto trae a la memoria el significado que los antiguos romanos otorgaban a la palabra dignitas; a saber: el prestigio de los hombres de estado y de los empleados públicos al servicio de la res publica. Aunque, por supuesto, la distinción otorgada a algunos "dignatarios" excepcionales y a unos cuantos notables contrasta con la dignidad que el estado constitucional debe garantizar a todos los ciudadanos por igual.

En este sentido, Jeremy Waldron llama la atención sobre el hecho paradójico de que el concepto igualitario de la dignidad humana sea el resultado de una generalización de dignidades particulares que, por otra parte, no deben perder del todo la connotación de "distinciones de excelencia": "Asociada en ese entonces a la diferenciación jerárquica de rango y estatus, actualmente la 'dignidad' transmite la idea según la cual todas las personas humanas pertenecen a un mismo rango, que es, efectivamente, uno muy alto." ${ }^{20}$ Waldron concibe este proceso de generalización de tal forma que todos los ciudadanos adquieren ahora el más alto rango posible, como lo sería, por ejemplo, aquel que anteriormente estaba reservado a la nobleza. Pero, irealmente puede capturarse así el significado de la igual dignidad de todo ser humano? Ni siquiera los precursores directos del concepto de dignidad humana en la filosofía de los estoicos y el humanismo romano (por ejemplo, Cicerón) ofrecieron un puente semántico hacia el significado igualitario del concepto moderno. En ese mismo periodo se encuentra una noción colectiva bien desarrollada de la dignitas humana, pero explicada en términos del estatus ontológico distinguido de los seres humanos en el cosmos y del rango particular del que disfrutan vis-à-vis formas de vida "inferiores", en virtud de las facultades propias de su especie tales como la razón y la reflexión. Ahora bien, el valor superior de la especie pudo haber justificado alguna clase de protección especial para la misma,

${ }^{19}$ Así, los derechos humanos no se oponen a la democracia, sino que son cooriginarios con ella. La relación entre ambos es de mutua presuposición: los derechos humanos hacen posibles los procesos democráticos sin los cuales no podrían promulgarse y concretarse en el interior del marco de un estado constitucional basado en los derechos civiles. Günther 2008.

${ }^{20}$ Waldron 2007, p. 201.

Diánoia, vol. LV, no. 64 (mayo 2010). 
pero no la inviolabilidad de la dignidad de la persona individual como fuente de exigencias normativas.

Faltan aún dos etapas decisivas en la genealogía del concepto. En primer lugar, a la universalización debe seguir la individualización; lo que está en juego es el valor del individuo en las relaciones horizontales entre diferentes seres humanos, y no el estatus de los "seres humanos" en su relación vertical con Dios, o con las criaturas "inferiores" en la escala evolutiva. En segundo lugar, la relativa superioridad de la humanidad y de sus miembros debe reemplazarse por el valor absoluto de todo ser humano; esto es, por la noción del valor único de cada persona. Estos dos pasos se dieron en Europa cuando la filosofía recuperó ideas provenientes de la tradición judeocristiana, un proceso al que quisiera referirme brevemente. ${ }^{21}$

El vínculo cercano entre las nociones de dignitas y persona ya se había propuesto en la Antigüedad, pero fue solamente a partir de las discusiones medievales sobre la creación de los seres humanos a imagen y semejanza de Dios cuando la persona individual logró liberarse de su dependencia respecto de un conjunto de roles sociales: todos tendrán que enfrentar el Juicio Final como personas únicas e irreemplazables. Otra etapa en la historia conceptual de la individualización estuvo representada por los escolásticos españoles en su búsqueda para distinguir los derechos subjetivos del sistema objetivo del derecho natural; ${ }^{22}$ pero los parámetros clave fueron finalmente establecidos con la moralización del concepto de libertad individual planteada por Hugo Grotius y Samuel Pufendorf. Kant, a su vez, radicalizó esta concepción en un concepto deontológico de autonomía; no obstante, el precio a pagar por la radicalidad de ese concepto fue otorgarle un estatus incorpóreo a la voluntad libre (Freien Willens) en el trascendental "reino de los fines". En esta concepción, la libertad consiste en la capacidad de legislar para uno mismo [autolegislación] y de obedecer leyes razonables que reflejen valores e intereses generalizables. La relación de los seres racionales entre sí está determinada por el reconocimiento recíproco de la universalidad de la voluntad legisladora de cada persona, por el cual cada persona deberá: "tratarse a sí misma y a todos los demás nunca como un simple medio sino siempre al mismo tiempo como fines en sí mismos". ${ }^{23}$

${ }^{21}$ Sobre el trasfondo teológico del concepto de los derechos humanos, véase el análisis de la historia de las ideas en Stein 2007, en particular el cap. 7. También Huber 1996, pp. 222-286.

${ }^{22}$ Böckenförde 2002, pp. 312-370.

${ }^{23}$ Kant 2003 (4: 432). 
El imperativo categórico define los límites de una esfera que debe permanecer absolutamente fuera del alcance de los otros. La "dignidad infinita" de cada persona consiste en la exigencia de que los otros respeten la inviolabilidad de esa esfera de voluntad libre. Pero el concepto de "dignidad humana" no adquirió importancia sistemática en Kant, puesto que la carga completa de la justificación descansa en la explicación filosófico-moral de la autonomía. Ahora bien, para poder entender lo que queremos decir con la expresión "dignidad humana", debe explicarse el "reino de los fines" en primer lugar. ${ }^{24}$

En la Doctrina del Derecho, Kant introduce los derechos humanos —o, más bien, el único derecho que toda persona puede exigir en virtud de su humanidad - mediante una referencia directa a la libertad de cada uno: "en la medida en que pueda coexistir con la libertad de los otros, de acuerdo con una ley universal". ${ }^{25}$ En Kant, asimismo, los derechos humanos derivan su contenido moral que se especifica en el lenguaje del derecho positivo, de una concepción universalista e individualista de la dignidad humana. No obstante, esta última se asimila a la idea de una libertad inteligible más allá del tiempo y del espacio; de ese modo se pierden precisamente aquellas connotaciones de estatus que le permitían fungir como enlace conceptual entre la moral y los derechos humanos. De manera que también se pierde la razón de ser del carácter legal de los derechos humanos; a saber, que éstos deben proteger la dignidad humana, que deriva sus connotaciones de autorrespeto y reconocimiento social de un estatus situado en un espacio y tiempo determinados: el de la ciudadanía democrática. ${ }^{26}$

\section{III}

La carga moral de los derechos coercitivos explica por qué la fundación de los estados constitucionales a finales del siglo XVIII surgió con una

${ }^{24}$ I. Kant (BA 78 oder Weischedel Bd IV, 68): "Im Reich der Zwecke hat alles entweder einen Preis, oder eine Würde. Was einen Preis hat, an dessen Stelle kann auch etwas anderes, als Äquivalent, gesetzt werden; was dagegen über allen Preis erhaben ist, mithin kein Äquivalent verstattet, das hat eine Würde" (veáse la versión en castellano en la nota 5).

${ }^{25}$ Kant 1994 (6: 237).

${ }^{26}$ Desde las premisas de la teoría de Kant no se necesita ninguna "mediación" entre el reino trascendental de la libertad y el reino fenoménico de la necesidad. Sin embargo, tan pronto como el carácter nouménico de la libre voluntad es "destrascendentalizado", debe salvarse la brecha conceptual entre la moral y el derecho. La concepción de la dignidad dependiente del estatus es la que provee esta conexión.

Diánoia, vol. LV, no. 64 (mayo 2010). 
tensión provocadora en el interior de las sociedades modernas. Sin duda, en todas partes existe en el ámbito social una diferencia entre la conducta real y las normas; sin embargo, la práctica sin precedentes de redactar constituciones dio lugar a una brecha utópica completamente diferente en la dimensión temporal. Por un lado, los derechos humanos pueden adquirir la calidad de derechos exigibles únicamente en el interior de una comunidad política particular, esto es, en el interior del estado-nación; pero, por otro, los derechos humanos están conectados con una demanda universal de validez que desborda toda frontera nacional. ${ }^{27}$ Esta contradicción sólo podría encontrar una solución razonable en una sociedad mundial constitucionalizada (no necesariamente con las características de una república mundial). ${ }^{28}$ Existe entonces, para empezar, una tensión dialéctica entre los derechos humanos y los derechos civiles establecidos, aunque en condiciones históricas favorables podría detonarse una dinámica de fortalecimiento mutuo.

No es mi intención sugerir la existencia de una dinámica autopropagadora (self-propelling) capaz de superar la tensión dialéctica entre exclusión e inclusión. Conseguir ampliar la protección de los derechos humanos en el interior de los estados-nación, o presionar para que se difundan más allá de las fronteras nacionales, nunca ha sido posible sin movimientos y luchas sociales y políticas, o sin la resistencia valiente a la opresión y la degradación. La batalla por implementar los

${ }^{27}$ Wellmer 1998. Para un sagaz análisis de las implicaciones de la brecha entre derechos humanos y derechos civiles, tanto para ciudadanos como para residentes inmigrantes dentro del estado-nación, cfr. Denninger 2009b.

${ }^{28}$ Acerca de la constitucionalización del derecho internacional, véanse Habermas 2006a, y 2009. La contradicción entre los derechos civiles y los derechos humanos no puede resolverse exclusivamente mediante la difusión global de estados constitucionales junto con el "derecho a tener derechos" (right to have rights) exigido por Hannah Arendt (teniendo en mente los ríos de personas desplazadas al final de la Segunda Guerra Mundial), pues el derecho internacional clásico deja las relaciones internacionales en un "estado de naturaleza". La necesidad de coordinación en la sociedad mundial que entre tanto se ha originado sólo podría satisfacerse a partir de una condición jurídica cosmopolita (en un sentido kantiano adaptado y contemporáneo). En este contexto debo corregir un grave malentendido en la introducción al número especial de Metaphilosophy, vol. 40, no. 1, 2009, p. 2 (y en el artículo de Andreas Føllesdal en el mismo número, pp. 85 ss.). Sin lugar a dudas, yo defiendo la extensión de las identidades políticas colectivas más allá de las fronteras de los Estados nacionales y de ninguna manera comparto las reservas de los liberales nacionalistas en este aspecto. Siendo un defensor de un sistema global multinivel de una sociedad mundial constitucionalizada, expongo otras razones por las que un gobierno mundial no es ni necesario ni realizable.

Diánoia, vol. LV, no. 64 (mayo 2010). 
derechos humanos continúa en la actualidad tanto en nuestros propios países, como, por ejemplo, en Irán o en China, en partes de África, en Rusia o en Kosovo. Cada vez que un solicitante de asilo es deportado en un aeropuerto a puertas cerradas, cada vez que un barco que lleva refugiados que escapan de la pobreza se vuelca en el cruce entre Libia y la isla italiana de Lampedusa, o cada vez que se dispara una bala en la cerca que divide la frontera con México, los ciudadanos de las naciones occidentales desarrolladas enfrentamos una cuestión inquietante. La primera declaración de los derechos humanos estableció un estándar que inspira a los refugiados, a todos los que han sido forzados a vivir en la miseria, a los que han sido excluidos y humillados; es un estándar que afirma que esos sufrimientos no son un destino natural. Con la traducción del primer derecho humano en derecho positivo surgió el deber legal de cumplir con requerimientos morales rigurosos, y esto es algo que ha quedado grabado en la memoria colectiva de la humanidad.

Los derechos humanos constituyen una utopía realista en la medida en que no proponen más imágenes engañosas de una utopía social que promete la felicidad colectiva, sino que fundan el ideal de una sociedad justa en las instituciones de los estados constitucionales. ${ }^{29}$ Sin duda, esta idea de la justicia que pretende trascender todo contexto introduce también una tensión problemática con las realidades sociales y políticas. Además de la fuerza meramente simbólica de los derechos humanos de algunas "democracias de fachada" que encontramos en América Latina y en otros lugares del mundo, ${ }^{30}$ la política de los derechos humanos de las Naciones Unidas revela la contradicción que existe entre difundir, por un lado, la retórica de los derechos humanos, y por el otro, abusar de ellos como medio para legitimar las políticas de poder usuales. Aunque también es cierto que la Asamblea General de la ONU ha promovido la codificación de los derechos humanos en el derecho internacional y la diferenciación de sus contenidos, por ejemplo, mediante la celebración de convenios de derechos humanos. Además, pueden señalarse algunos avances en la institucionalización de los derechos humanos en los procedimientos de petición individual, en los informes periódicos sobre la situación de los derechos humanos en países particulares y, sobre todo, en la creación de cortes internacionales, como la Corte Europea de Derechos Humanos, diversos tribunales de crímenes de guerra y la Corte Penal Internacional. Más notables aún son

\footnotetext{
${ }^{29}$ Bloch 1987.

${ }^{30}$ Neves 2007.
} 
las intervenciones humanitarias autorizadas por el Consejo de Seguridad en nombre de la comunidad internacional, algunas veces incluso contra la voluntad de gobiernos soberanos. No obstante, justamente estos casos revelan la naturaleza problemática de intentar promover un orden mundial que en el presente se encuentra institucionalizado sólo de manera fragmentaria. En este sentido, su carácter ambiguo es aún más grave que el fracaso de los intentos legítimos para alcanzar su institucionalización, ya que pone en entredicho y desacredita los estándares morales mismos. ${ }^{31}$

Sólo tendríamos que recordar las decisiones altamente selectivas y cortas de vista de un Consejo de Seguridad no representativo y muy lejano a la imparcialidad, o las incompetentes y poco comprometidas implementaciones de las intervenciones [militares] autorizadas y sus catastróficos fracasos (Somalia, Ruanda, Darfur). Estas supuestas operaciones de vigilancia continúan siendo conducidas como guerras en las que los militares dan por descontada la muerte y el sufrimiento de civiles inocentes al considerarlos "daños colaterales" (como en Kosovo). Las potencias interventoras tendrían aún que demostrar en un caso concreto que son capaces de canalizar la energía y la resistencia necesarias para la construcción de un estado, o para reconstruir la infraestructura destruida o dilapidada en las regiones aún no pacificadas (como en el caso de Afganistán). Cuando la política de derechos humanos se convierte en una simple hoja de parra para encubrir e imponer los intereses de los más poderosos, o cuando una superpotencia desprecia abiertamente la Carta de la ONU y se arroga unilateralmente el derecho de intervención e invade un país, violando el derecho internacional humanitario, y al mismo tiempo pretende justificarse en nombre de valores universales, parecería confimar la sospecha de que el programa de los derechos humanos consiste justamente en su abuso imperialista. ${ }^{32}$

${ }^{31}$ Además, "las políticas gubernamentales de derechos" humanos dominantes en la actualidad están destruyendo progresivamente el vínculo entre los derechos humanos y la democracia; véase la nota al pie 19 en conexión con Maus 1999. Sobre esta tendencia, véase también Günther inédito, 2009a.

${ }^{32}$ Cfr. Schmitt 1988 [1938], y 1994 [1945]. Carl Schmitt fue el primero en formular explícitamente esta sospecha. Él denunció los derechos humanos ante todo como una ideología que invoca la guerra como un medio legítimo para resolver conflictos internacionales. Schmitt ya había hecho responsable al ideal pacifista de la política wilsoniana de paz por el hecho de que "la distinción entre guerra justa e injusta está dando origen a una distinción, aún más profunda, aguda y total, entre amigo y enemigo". En el dominio brutal de las relaciones internacionales, señaló Schmitt, la moralización de los enemigos constituye un método desastroso para

Diánoia, vol. LV, no. 64 (mayo 2010). 
Esta tensión entre idea y realidad, que se manifestó en la realidad misma cuando los derechos humanos fueron traducidos en derecho positivo, nos confronta hoy con el reto de pensar y actuar de forma realista sin traicionar el impulso utópico. Esta ambivalencia nos puede llevar muy fácilmente a la tentación de adoptar una perspectiva idealista pero no comprometida en la defensa de requerimientos morales rigoristas o, por el contrario, a la postura cínica de los así llamados "realistas". En la medida en que ya no es considerado realista seguir a Carl Schmitt en su rechazo completo al programa de los derechos humanos, ya que su fuerza subversiva entre tanto ha impregnado los poros de todas las regiones del mundo, el "realismo" asume hoy una forma diferente. La crítica directa y desenmascaradora ahora está siendo reemplazada por otra más débil y deflacionaria; este nuevo minimalismo debilita las exigencias de los derechos humanos al arrancarles su fuerza moral esencial; esto es: la protección de la igual dignidad de todo ser humano.

Siguiendo a John Rawls, Kenneth Baynes caracteriza este enfoque como una concepción "política" ${ }^{33}$ de los derechos humanos, en contraste con las nociones del derecho natural de unos derechos "inherentes" que se supone posee cada persona en virtud de su naturaleza misma: "los derechos humanos son concebidos como condiciones para la inclusión en una comunidad política". ${ }^{34}$ Este primer paso sigue la línea del argumento anterior; pero el paso problemático es el siguiente, ya que anula el significado moral de esta inclusión; a saber: que toda persona debe ser respetada en su dignidad humana como un sujeto de iguales derechos. Desde esta segunda perspectiva, el núcleo de todo el enfoque se reduce a meros asuntos de política internacional de derechos humanos. ${ }^{35}$ Con ello, la fuente normativa de esta dinámica es ignorada; esto

oscurecer los intereses propios, pues el atacante se protege y se esconde tras la fachada, en apariencia transparente, de una abolición de la guerra supuestamente racional y humanitaria. Sin embargo, la crítica a la "moralización" del derecho en nombre de los derechos humanos es odiosa justamente porque no da en el blanco; a saber, la transposición de los contenidos morales al ámbito del derecho coercitivo. En la medida en que la prohibición de la guerra lleva actualmente a la domesticación legal de las relaciones internacionales, la distinción entre guerras "justas" e "injustas" es reemplazada por la distinción entre guerras "legales" e "ilegales". Sobre esto, véase Günther 1994, pp. 137-157.

${ }^{33}$ Baynes 2009b.

${ }^{34}$ Baynes 2009a.

${ }^{35}$ Baynes 2009a, p. 7: "Los derechos humanos se entienden primordialmente como normas internacionales que buscan proteger intereses humanos fundamentales y/o asegurar a los individuos la oportunidad de participar como miembros en una sociedad política." Charles Beitz inicia su nuevo libro The Idea of Human Rights

Diánoia, vol. LV, no. 64 (mayo 2010). 
es, la tensión que se mantiene entre los derechos humanos universales y los derechos civiles particulares que existe incluso en el interior de estados constitucionales ejemplares. ${ }^{36}$

Desde ese punto de vista estrecho, la difusión global de los derechos humanos requiere una justificación independiente. Dicha justificación se ofrece como un argumento que sostiene que en las relaciones internacionales las obligaciones morales entre los estados (y entre los ciudadanos) se originan en la interconexión sistémica creciente de una sociedad mundial cada vez más interdependiente. ${ }^{37}$ Las exigencias normativas de inclusión se habrían originado inicialmente en las dependencias recíprocas de interacciones fácticamente establecidas. ${ }^{38}$ Este argumento tiene cierta fuerza explicativa ante la pregunta empírica de cómo se ha despertado una sensibilidad para dar respuesta a las exigencias legítimas de inclusión, esgrimidas por poblaciones marginadas y desfavorecidas, en nuestras sociedades relativamente prósperas. Sin embargo, estas mismas exigencias normativas tienen como fundamento nociones morales universalistas que se han incorporado desde hace mucho tiempo a los derechos humanos y civiles de las constituciones democráticas, a través de una idea de dignidad humana dependiente del estatus. Únicamente este vínculo interno entre la dignidad humana y los derechos humanos puede dar lugar a la fusión explosiva de contenidos morales con el derecho coercitivo; en otras palabras, en el derecho como el medio por el cual debe realizarse la construcción de órdenes políticos justos.

Investir el derecho con una carga moral es el legado de las revoluciones constitucionales del siglo XVIII. Neutralizar esta tensión implicaría abandonar el entendimiento dinámico que hace que los ciudadanos de

(2009, p. 1) con la siguiente observación: "los derechos humanos se han convertido en una elaborada práctica internacional".

${ }^{36}$ Para una crítica convincente de este enfoque minimalista, $c f r$. Forst, inédito, 2009: "En general es desorientador enfatizar la función político-legal de tales derechos para proveer razones para una política de intervención legítima. Eso es poner el carro delante de los caballos. Primero necesitamos construir (o encontrar) un conjunto justificable de derechos humanos que tienen que ser respetados por las autoridades políticas, y sólo después podemos preguntarnos qué tipos de estructuras legales se requieren a nivel internacional para supervisar lo anterior y ayudar a asegurar que la autoridad política se ejerza de esa forma."

${ }^{37}$ Cohen 2004.

${ }^{38}$ Baynes 2009b, p. 382: "los derechos y los deberes correspondientes se crean por la relación especial en la que se encuentran los individuos entre sí, más que por el hecho de ser exigencias que los individuos tienen simplemente en virtud de su humanidad".

Diánoia, vol. LV, no. 64 (mayo 2010). 
nuestras sociedades, parcialmente liberales, estén dispuestos a lograr una realización cada más exhaustiva de los derechos ya existentes, dejándolos, en cambio, expuestos al peligro siempre presente y agudo de la erosión de tales derechos.

[Versión en castellano: Javier Aguirre Román, revisada por Eduardo Mendieta y María Herrera.]

\section{BIBLIOGRAFÍA}

Baynes, K., 2009a, "Discourse Ethics and the Political Conception of Human Rights", Ethics and Global Policy, vol. 2, no. 1, pp. 1-21.

_, 2009 b, "Toward a Political Conception of Human Rights", Philosophy and Social Criticism, vol. 35, no. 4, pp. 371-390.

Beitz, Ch., 2009, The Idea of Human Rights, Oxford University Press, Oxford.

Bernstorff, J.V., inédito, 2008, "Luftsicherheitsgesetz und Menschenwürde Zum unbedingten Vorrang staatlicher Achtungspflichten im Anwendungsbereich von Art 1 GG".

Bloch, E., 1987, Natural Law and Human Dignity, The MIT Press, Cambridge, Mass..

Böckenförde, E., 2002, Geschichte der Rechts- und Staatsphilosophie, Mohr Siebeck, Tubinga, pp. 312-370.

Brugger, W., U. Neumann y St. Kirste (comps.), 2008, Rechtsphilosophie im 21. Jahrhundert, Suhrkamp, Fráncfort del Meno.

Brunkhorst, H., W.R. Köhler y M. Lutz-Bachmann (comps.), 1999, Recht auf Menschenrechte, Suhrkamp, Fráncfort del Meno.

Cohen, J., 2004, "Minimalism about Human Rights: The Most We Can Hope for," The Journal of Political Philosophy, vol. 12, no. 2, pp. 190-213.

Denninger, E., inédito, 2009a, "Der Menschenwürdesatz im Grundgesetz und seine Entwicklung in der Verfassungsrechsprechung".

—, $2009 \mathrm{~b}$, “'Die Rechte der Anderen'. Menschen und Bürgerrechte im Widerstreit", Kritische Justiz, vol. 42, no. 3, pp. 226-238.

Flynn, J., 2003, "Habermas on Human Rights: Law, Morality, and International Dialogue", Social Theory and Practice, vol. 29, no. 3, pp. 431-457.

Føllesdal, A., 2009, "Universal Human Rights as a Shared Political Identity: Impossible? Necessary? Sufficient?", Metaphilosophy, vol. 40, no. 1, pp. 7791.

Forst, R., inédito, 2009, "The Justification of Human Rights and the Basic Right to Justification. A Reflexive Approach", próximo a publicarse en Ethics.

Gardbaum, S., 2003, "The Horizontal Effect of Constitutional Rights", Michigan Law Review, vol. 102, pp. 388-459.

Gosepath, S. y G. Lohmann (comps.), 1998, Philosophie der Menschenrechte, Suhrkamp, Fráncfort del Meno, pp. 265-291. 
Günther, K., inédito, 2009a, "Die Definition und Fortentwicklung der Menschenrechte als Akt kollektiver Selbstbestimmung".

—_ inédito, 2009b, "Vom vertikalen zum horizontalen Verständnis der Menschenrechte?"

_, 2008 , "Liberale und diskurstheoretische Deutungen der Menschenrechte", en Brugger, Neumann y Kirste 2008, pp. 338-359.

—_, 1994, "Kampf gegen das Bose?", Kritische Justiz, no. 27, pp. 135-157.

Habermas, J., 2009, "The Constitutionalization of International Law and the Legitimation Problems of a Constitution for World Society", en Europe, The Faltering Project, Polity Press, Cambridge, Mass.

_ $2006 \mathrm{a}$, "Does the Constitutionalization of International Law Still Have a Chance?", en The Divided West, Polity Press, Cambridge, Mass.

_, 2006 b, "Sobre la arquitectónica de la diferenciación de discursos", en Entre naturalismo y religión, Paidós, Madrid, pp. 83-103.

_ 2001 , "Constitutional Democracy: A Paradoxical Union of Contradictory Principles?", Political Theory, no. 29, pp. 766-781.

—_, 1998, Facticidad y validez, trad. Manuel Jiménez Redondo, Trotta, Madrid.

Huber, W., 1996, Gerechtigkeit und Recht. Grundlagen einer christlichen Rechtsethik, Chr. Kaiser, Gütersloh.

Kant, I., 2003, Fundamentación de la metafísica de las costumbres, trad. Manuel García Morente, Ediciones Encuentro, Madrid.

_, 1994, Metafísica de las costumbres, trad. Adela Cortina y Jesús Conill, Tecnos, Madrid.

—_, 1968, Kants Werke: Akademie Textausgabe: unveränderter photomechanischer Abdruck des Textes der von der Preussischen Akademie der Wissenschaften 1902 begonnenen Ausgabe von Kants gesammelten Schriften, De Gruyter, Berlín, 9 vols.

Lohmann, G., 2005, "Die Menschenrechte: unteilbar und gleichgewichtig?", en Studien zu Grund- und Menschenrechten, vol. 11, Menschenrechtszentrum der Universität Potsdam/Potsdam Universitätsverlag, Potsdam, pp. 5-20.

_ 1998 , "Menschenrechte zwischen Moral und Recht", en Gosepath y Lohmann 1998, pp. 62-95.

Maus, I., 1999, "Menschenrechte als Ermächtigungsnormen internationaler Politik", en Brunkhorst et al. 1999, pp. 276-291.

McCrudden, C., 2008, "Human Dignity and Judicial Interpretation of Human Rights", The European Journal of International Law, vol. 19, no. 4, pp. 655724.

Neves, M., 2007, "The Symbolic Forms of Human Rights", Philosophy and Social Criticism, vol. 33, pp. 411-444.

Schmitt, C., 1994, Das international-rechtliche Verbrechen des Angriffsgrieges, H. Quaritsch, Duncker und Humblot, Berlín.

__, 1988, Die Wendung zum diskrimierenden Kriegsbegriff, Duncker und Humblot, Berlín.

Diánoia, vol. LV, no. 64 (mayo 2010). 
Stein, T., 2007, Himmlische Quellen und irdisches Recht, Campus, Fráncfort del Meno.

Tinnevelt, R. y H. De Schutter, 2009, "Introduction: Global Democracy and Exclusion", Metaphilosophy, vol. 40, no. 1, pp. 1-7.

Waldron, J., 2007, "Dignity and Rank", Archives Européennes de Sociologie, vol. 48, pp. 201-237.

Wellmer, A., 1998, "Menschenrechte und Demokratie", en Gosepath y Lohmann 1998, pp. 265-291.

Recibido el 18 de febrero de 2010; aceptado el 10 de marzo de 2010. 